DRUG POINTS

\title{
Ciprofloxacin interacts with thyroid replacement therapy
}

John G Cooper, Knut Harboe, Sofia K Frost, Øyvind Skadberg

Department of Medicine, Stavange University Hospital, PO Box 8100, 4068 Stavanger, Norway John G Cooper endocrinologist

Department of Orthopaedic Surgery, Stavanger University Hospital Knut Harboe senior house officer

Department of Medical Biochemistry,

Stavanger

University Hospital

Øyvind Skadberg

consultant physician

Regional Drug Information Centre,

Haukeland

University Hospital,

5021 Bergen,

Norway

Sofia K Frost

pharmacis

Correspondence to:

J Cooper

john.cooper@

isf.uib.no

BMJ 2005;330:1009
We report two cases of unexplained hypothyroidism in patients taking oral ciprofloxacin (figure). Nursing staff gave levothyroxine. Prescription charts showed no drug administration errors. Patients did not have nausea, vomiting, or diarrhoea.

\section{Case reports}

\section{Case 1}

An 80 year old woman with advanced thyroid cancer had maintained suppressed concentrations of thyroid stimulating hormone and stable free thyroxine by taking $125 \mu \mathrm{g}$ levothyroxine daily. She was admitted with a pathological fracture of the femur and complicating osteomyelitis. After four weeks' treatment with oral ciprofloxacin (750 mg twice a day), intravenous dicloxacillin, and subcutaneous heparin, she complained of increasing tiredness. Her thyroid stimulating hormone concentration had increased to $44 \mathrm{mIU} / \mathrm{l}$ (reference range 0.4-4.4 mIU/1), free thyroxine had fallen to $4 \mathrm{pmol} / \mathrm{l}(12-22 \mathrm{pmol} / \mathrm{l})$, and free triiodothyronine was $1.0 \mathrm{pmol} / \mathrm{l}(3.1-6.3 \mathrm{pmol} / \mathrm{l})$

Increasing levothyroxine to $200 \mu \mathrm{g}$ daily had no effect. We reduced levothyroxine to $125 \mu \mathrm{g}$ daily and stopped ciprofloxacin, and thyroid function tests rapidly became normal. Other drugs (alfacalcidiol, propranolol, ranitidine, furosemide, methenamine hippurate, paracetamol, morphine, and ondansetron) were unchanged. We continued to give dicloxacillin and heparin as thyroid function returned to normal (figure). The patient died of metastatic thyroid cancer three weeks after discharge.

Case 2

A 79 year old woman with rheumatoid arthritis, manic depression, cardiac failure, chronic obstructive airways disease, and hypothyroidism was admitted with a wound infection after a transfemoral amputation. She had maintained stable thyroid function tests on a daily dose of $150 \mu \mathrm{g}$ levothyroxine. After three weeks' treatment with oral ciprofloxacin (500 mg twice a day), her concentration of thyroid stimulating hormone had increased from 1.6 to $19 \mathrm{mIU} / \mathrm{l}$ and free thyroxine had fallen from 22 to $13 \mathrm{pmol} / \mathrm{l}$. Switching from concomitant administration of levothyroxine and ciprofloxacin to administering the drugs with a six hour gap resulted in rapid normalisation of the thyroid function tests (figure). Other drugs (zuclopenthixol, enalapril, bumetanide, prednisolone, folic acid, lactulose, acetylcysteine, hydroxychloroquine, paracetamol, ipratropium bromide, salbutamol, nystatin) remained unchanged.

\section{Discussion}

Oral ciprofloxacin may interact with levothyroxine if they are given together. The most plausible explanation is that ciprofloxacin decreases the absorption of levothyroxine. Antacids, laxatives, colestipol, colestyramine, ferrous sulphate, sulcralfate, and raloxifene have been reported to decrease the absorption of levothyroxine, ${ }^{1-3}$ but we have not found any previous reports of an interaction between levothyroxine and ciprofloxacin. Neither have the WHO Collaborating Centre for International Drug
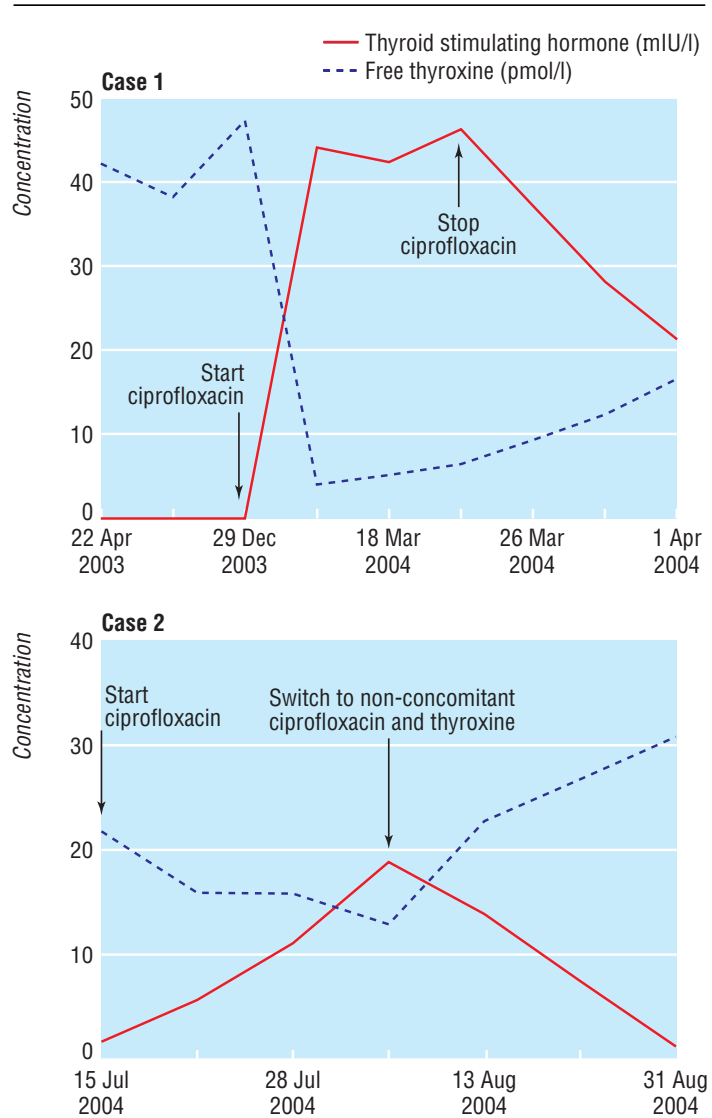

Unexplained hypothyroidism in patients taking oral ciprofloxacin

Monitoring nor the manufacturer of ciprofloxacin. This interaction is important for patients taking long courses of ciprofloxacin. It is prudent to advise patients to take levothyroxine and other drugs at different times.

Funding: None.

Competing interests: None declared.

1 Mersebach H, Rasmussen AK, Kirkegaard L, Feldt-Rasmussen U. Intestinal adsorption of levothyroxine by antacids and laxatives: case stories and in vitro experiments. Pharmacol Toxicol 1999;84:107-9.

2 Surks MI, Sievert R. Drugs and thyroid function. N Engl J Med 1995;333; 1688-94.

3 Siraj ES, Gupta MK, Reddy SS. Raloxifene causing malabsorption of levothyroxine. Arch Intern Med 2003;163:1367-70. (Accepted 1 February 2005)

\section{Endpiece}

Life

First you are young; then you are middle aged; then you are old; then you are wonderful.

Lady Diana Cooper (1892-1986), wife of Alfred Duff Cooper, English politician and diplomat

Fred Charatan, retired geriatric physician, Florida 